IJBPAS, February, 2021, 10(2): 613-629

ISSN: 2277-4998

International Journal of Biology, Pharmacy

and Allied Seiences (IJBPAS)

'A Bridge Betuen Caboratory and QRendo'

WwW.jibpas.com

AMALGAMATION OF DIGITAL AND MANUAL WORKFLOW FOR THE FULL MOUTH ESTHETIC AND FUNCTIONAL REHABILITATION OF A PATIENT WITH AMELOGENESIS IMPERFECTA TO IMPROVE PATIENT SATISFACTION AND QUALITY OF LIFE - A CASE REPORT

\title{
RAJARAMAN $\mathbf{V}^{1 *}$, MAITI $\mathrm{S}^{2}$, NALLASWAMY $\mathrm{D}^{3}$, HARIHARAN A ${ }^{4}$ AND TULSANI $\mathrm{M}^{5}$
}

1: Postgraduate student (MDS), Department of Prosthodontics \& Implantology, Saveetha Dental College, Saveetha Institute of Medical and Technical Sciences, Chennai, India

2: Assistant Professor, Department of Prosthodontics \& Implantology, Saveetha Dental College, Saveetha Institute of Medical and Technical Sciences, Chennai, India

3: Professor \& Director of Academics, Saveetha Dental College, Saveetha Institute of Medical and Technical Sciences, Chennai, India

4: Postgraduate student (MDS), Department of Prosthodontics \& Implantology, Saveetha Dental College, Saveetha Institute of Medical and Technical Sciences, Chennai, India

5: Postgraduate student (MDS), Department of Prosthodontics \& Implantology, Saveetha Dental College, Saveetha Institute of Medical and Technical Sciences, Chennai, India

*Corresponding Author: Vaishnavi Rajaraman: E Mail: drvaish.sav@gmail.com; Ph. No. :

8779565950

Received $15^{\text {th }}$ April 2020; Revised $28^{\text {th }}$ May 2020; Accepted $24^{\text {th }}$ July 2020; Available online $1^{\text {st }}$ Feb. 2021

https://doi.org/10.31032/IJBPAS/2021/10.2.5386

ABSTRACT

Full mouth rehabilitation is a very challenging and comprehensive treatment protocol for most clinicians. In recent years a shifting trend towards digital workflow has been observed in dentistry, specially pertaining to prosthodontics and smile makeover. It requires intensive understanding of the concepts and fine skills, to execute and establish successful clinical outcomes. Various conditions of oral cavity may require full mouth rehabilitation. One such disorder is Amelogenesis Imperfecta (AI), mainly for 2 purposes: esthetics and preserving the 
crown integrity. This disorder represents a group of developmental conditions of genetic origin that affect the structure and clinical appearance of enamel of all or nearly all the teeth in a more or less equal manner. AI is a condition that inadvertently reduces oral health-related quality of life and may cause physiological problems. This case report describes a combined digital and manual workflow to achieve a successful outcome in full mouth rehabilitation of a patient presented with Amelogenesis Imperfecta. It also highlights the completion of treatment procedures in a short span with minimal clinical appointments.

Keywords: Amelogenesis Imperfecta, digital workflow, enamel hypoplasia, esthetics, full mouth rehabilitation, hypoplastic teeth

\section{INTRODUCTION}

Amelogenesis imperfecta (AI), is a group of hereditary diseases that affect the tooth enamel in either quality or quantity. The prevalence of this disorder ranges from 1:700 to $1: 14000$, depending on the population [14]. The uncertainty of the exact incidence of amelogenesis imperfecta is what makes the treatment plan difficult and challenging. There are around at least 14 types of amelogenesis imperfecta described by researchers [3-5]. These types are differentiated by their pattern of inheritance and specific dental abnormalities due to mutations in the AMELX, ENAM, MMP20, and $F A M 83 H$ genes $[\mathbf{4}, 6-9]$. These genes contain the instructions for synthesis of proteins that are necessary for the formation of enamel. Teeth with defective enamel are abnormally thin or soft, hence weak and easily damaged. The affected dentition may have a yellow or brown color [10-12].
Additionally, amelogenesis imperfecta can occur alone without any other signs and symptoms or as part of a syndrome affecting multiple parts of the body [5, 13-15].

Amelogenesis imperfecta is a condition that involves discolored, pitted or grooved teeth, prone to accelerated wear and breakdown. This condition could possibly affect primary and permanent dentition. It is associated with crown malformation and abnormal enamel density $[1,3,16,17]$. Depending on the type of AI, clinical features of patients might vary. The classification of AI is primarily on the triad of clinical, radiographic, and histologic appearance of the enamel defect as well as the mode of inheritance of the disorder [18, 19]. AI has been categorized as hypoplastic (autosomal dominant/ autosomal recessive/xlinked dominant), hypocalcified (autosomal dominant/ autosomal recessive), hypomaturation (autosomal recessive/x- 
linked recessive/ autosomal dominant) and hypoplastic-hypomaturation types. Hypoplastic AI represents 60 to $73 \%$ of all cases, hypomaturation AI represents 20 to $40 \%$, and hypocalcification AI represents $7 \%$ [20-24].

The challenging aspects for this case included the soft texture of enamel, the apt selection of dental material for prosthesis, the bonding protocol, the decision of veneer versus full coverage restoration, the masking of the severe discolouration present and the most important one being the time constraint in the complete treatment procedure. This case report presents a successful fullmouth rehabilitation of a patient with hypoplastic AI using a combined digital and manual workflow to achieve the desired outcome in a short span with minimal clinical appointments.

\section{PRESENTATION OF CASE}

A 22-year-old male patient reported to the Department of Prosthodontics, Saveetha Dental College and Hospital, with a chief complaint of yellow to brownish discoloration of all teeth since 10-12 years. The patient also reported a dental history of discolored deciduous teeth. No medical history or family history was reported, relevant to the same. On clinical examination intraorally, the patient had a complete set of permanent dentition with no missing teeth. Maxillary and mandibular teeth showed yellowish brown discoloration with normal morphology of crown structure and mild attrition of teeth (Figure 1). The soft tissue of the patient was firm in consistency and firmly attached to the underlying alveolar bone with adequate keratinization.

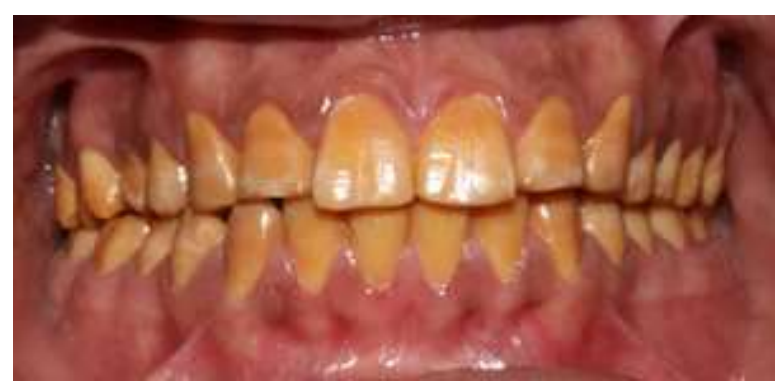

Figure 1: Intraoral frontal view of the patient showing yellowish brown discoloration There was no evidence of chipping of enamel provisional diagnosis of hypoplastic AI was and the consistency of enamel was medium (between soft to hard). Smile line of the provided and panoramic radiograph was advised. This radiograph showed the patient was medium, with a papillary smile. presence of a thin layer of enamel with radio On the basis of clinical examination, a density of enamel more than dentin and 
confirmed the final diagnosis of hypoplastic AI.

\section{TREATMENT}

PLAN

AND MANAGEMENT

To protect the crown structure with structural support as well as provide excellent esthetics, a treatment plan was devised which involved full veneer restorations of the entire dentition. The lower left first molar was grossly decayed and hence was extracted. The choice of material used for this was zirconia coping structure layered with ceramic for the maxillary and mandibular arch, owing to the severe discoloration of the dentition.

After obtaining informed consent for the treatment, entire treatment was planned and completed in 6 clinical appointments as follows-

- Appt. 1: Photographs (with patient's consent), Diagnostic impressions with irreversible hydrocolloid (Zhermack, Tropicalgin), Facebow record and jaw relation for diagnostic mounting (Figure 2).

- Appt. 2: Gross tooth preparations and temporization (Figure 3).

- Appt. 3: Final tooth preparations, Master impressions of maxillary and mandibular arches (Figure 4) with vinyl polysiloxane material
(Zhermack elite $\mathrm{HD}+$ ) and temporization. Final Face-bow record and jaw relation

- Appt. 4: Zirconia coping and monolithic trial (Figure 6) of digitally designed (Figure 7) prosthesis

- Appt. 5: Ceramic bisque trial and corrections followed by final cementation after glazing of prosthesis and maxillary arch impression for night guard (Figure 8).

- Appt. 6: Delivery of the night guard and oral hygiene instructions given.

the existing centric relation was confirmed with a bilateral manipulative technique (Dawson technique). Vertical dimension (VD) at rest (VDR) and occlusion (VDO) was determined. It was deciphered to restore in the existing VD. Intraoral diagnostic impression (Tropicalgin, Zhermack ${ }^{\circledR}$ ) was taken and mounted onto the semi-adjustable articulator (STRATOS 300, Ivoclar $($ ) with the help of facebow record and inter occlusal records using bite registration paste (Virtual CADbite $\left.{ }^{\circledR}\right)$. The diagnostic models were scanned in a lab scanner (Medit T500®) and a digital workflow was planned for the patient. A diagnostic wax up was done for 
maxillary and mandibular arches to establish occlusion (Figure 2).

Temporization was performed with gross tooth preparation with poly-methyl methacrylate material (Figure 3), at an existing vertical dimension, was delivered to the patient and was observed for any changes related to the stomatognathic system.
Shade determination (VITA classic shade guide $(\mathbb{R})$ was done according to the facial complexion keeping in mind, to mask the existing discolored teeth. The maxillary and mandibular teeth were prepared in the following order: right posterior, left posterior and lastly the anterior teeth were prepared.

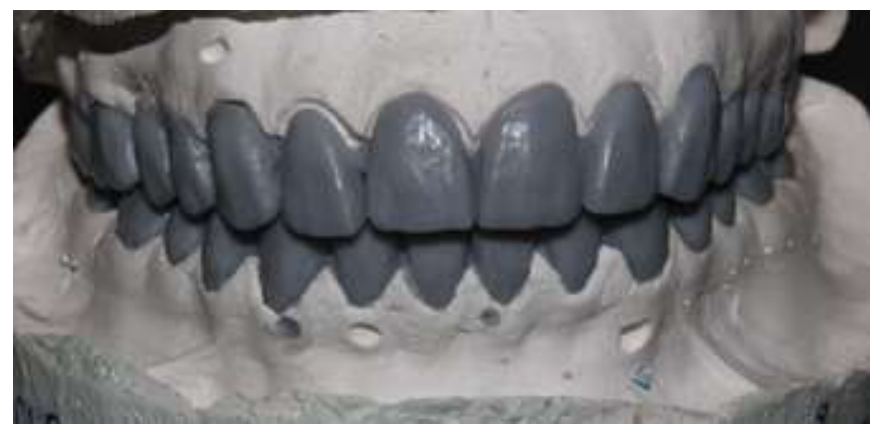

Figure 2: Diagnostic wax up

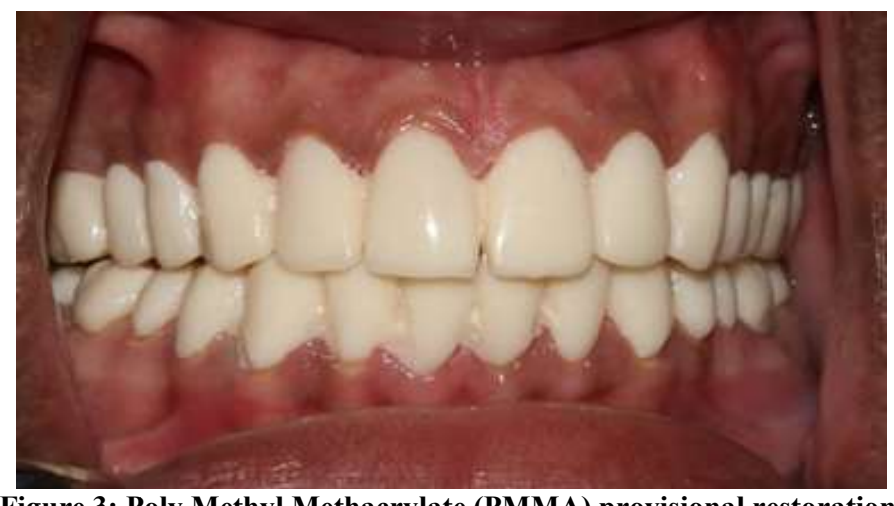

Figure 3: Poly Methyl Methacrylate (PMMA) provisional restoration

Prefabricated provisiona restoration were Once satisfied, gingival retraction was milled with Poly Methyl Methacrylate performed to expose all equigingival margins (PMMA) based on the diagnostic wax up. of the tooth preparation in the posterior teeth The provisional restorations are inserted in the mouth and anterior guidance was determined by all excursive movements from centric relation. and subgingival margins in the anterior teeth, prior to impression making. The margins were given so as to shift the demarcation of prosthesis and tooth margins below the free 
gingiva. For gingival retraction procedure, a double cord technique was used, a \#000 first cord and a \#00 second cord, with the cords soaked in local anaesthetic solution containing adrenaline (ULTRAPAK knitted cord). A master impression of the prepared arches was made after meticulous and conservative gingival retraction procedure with two stage putty wash technique (Elite HD+, Zhermack ${ }^{\circledR}$ ) and a final jaw relation was recorded using pattern resin (Pattern Resin LS, GC®) and the existing modified temporaries (Figure 4). Digital design was fabricated with anatomic copings in the maxillary and mandibular right first premolar to left premolar and monolithic zirconia crowns for maxillary and mandibular second premolars, first molars, second molars using 3Shape Trios $(\mathbb{2}$ and were milled in zirconia (Figure 5). Zirconia coping trial was done and the jaw relation verified for clearance for the ceramic layering (Figure 6).
Ceramic layering was done with A2 shade (VITA classic shade guide ${ }^{\circledR}$ ), using the index of the digital design and temporaries as a guide. Ceramic Bisque trial was done intraorally, for any corrections required in occlusion or aesthetics. The occlusion was examined with T-scan (T-Scan ${ }^{\mathrm{TM}}$ Novus $^{\mathrm{TM}}$ ) and a canine guided occlusion was obtained (Figure 7) [25-28].

The esthetics of the prosthesis was determined using the Smile Esthetic Index (SEI) with a score of 5 preoperatively and improved score of 9 postoperatively (Table 1) $(29,30)$. Once canine guided occlusion was established, final glazing was done and cemented with resin modified GIC luting cement (Figure 8). The drastic improvement of esthetics from preoperative to postoperative smile was evident (Figure 9) and close up photographs of anterior teeth were taken to show the emergence profile (Figure 10).

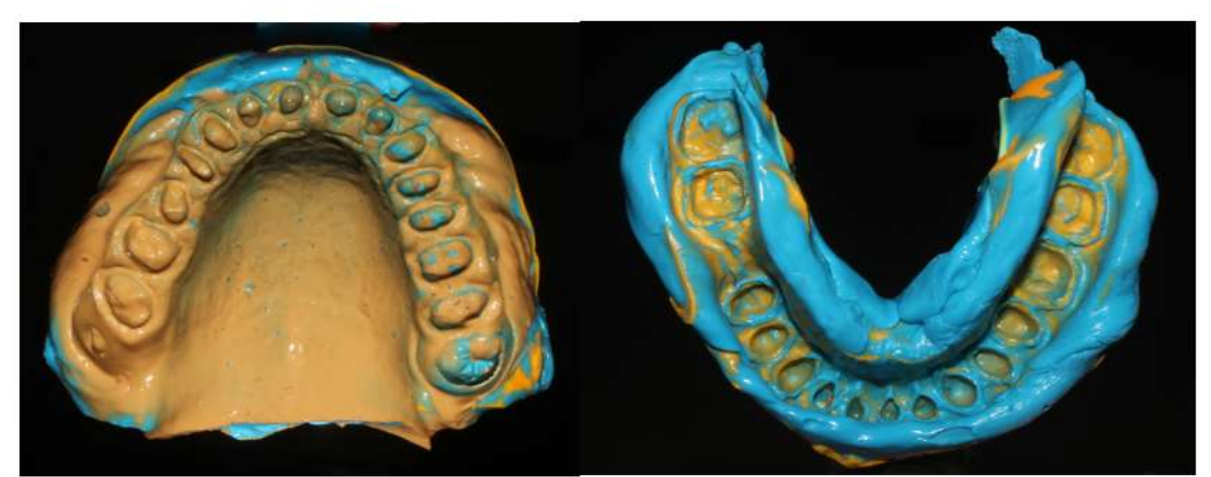

Figure 4: Master impression of the prepared arches was made after meticulous and conservative gingival retraction procedure with two stage putty wash technique (Elite HD+, Zhermack ${ }^{\circledR}$ ) 

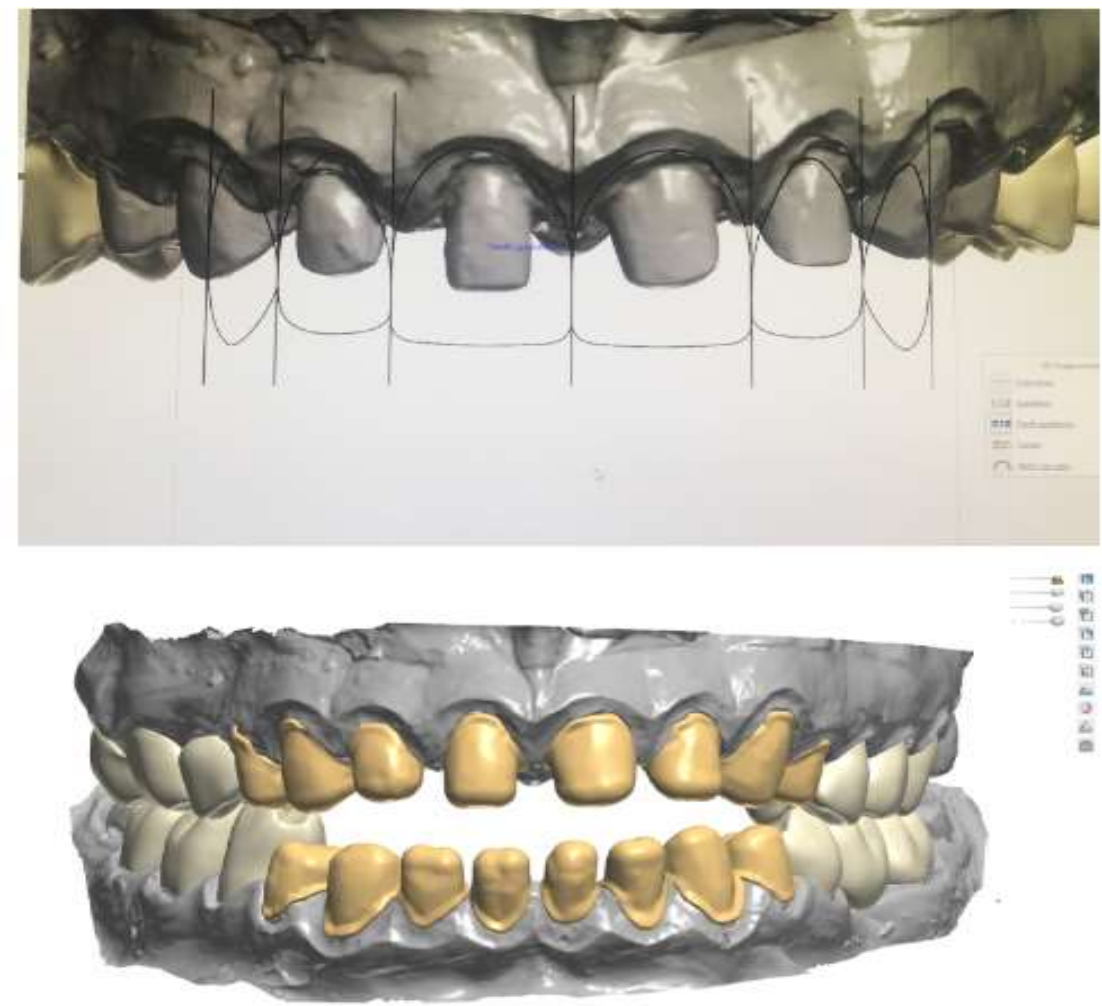

Figure 5: Digital design for anatomic copings in the maxillary and mandibular arches using 3Shape Trios ${ }^{\circledR}$

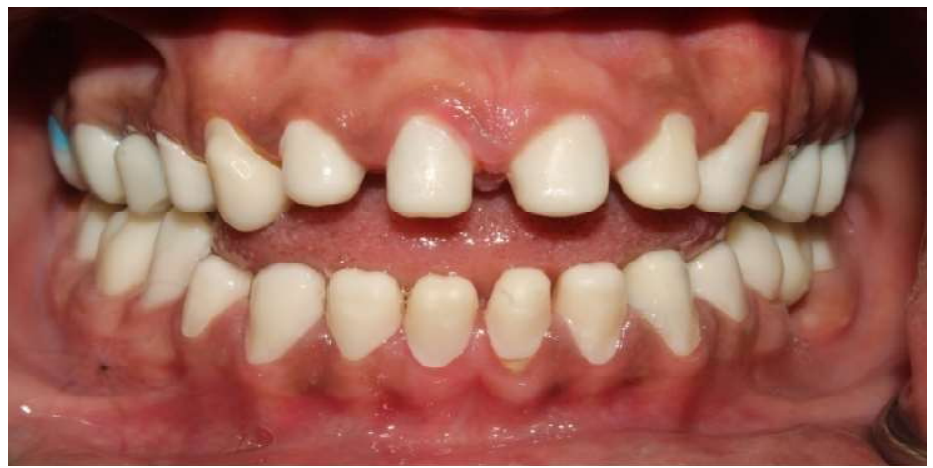

Figure 6: Zirconia coping trial with posterior monolithic zirconia

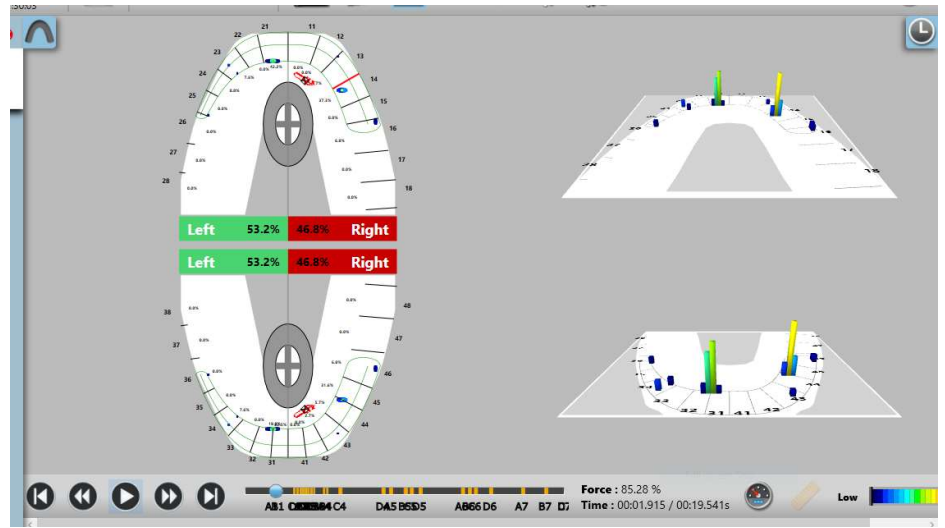

Figure 7: T-scan evaluation of the bisque ceramic trial showing non-uniform contacts that need to be equilibrated 
Table 1: Smile Esthetic Index (SEI) used to evaluate the esthetic outcome of the final prosthesis

\begin{tabular}{|c|c|c|c|}
\hline S.NO & CRITERIA & $\begin{array}{c}\text { PREOPERATIVE } \\
\text { ANSWERS } \\
(\mathrm{YES}=1, \mathrm{NO}=0) \\
\end{array}$ & $\begin{array}{c}\text { POSTOPERATIVE } \\
\text { ANSWERS } \\
(\text { YES }=1, \text { NO=0) }\end{array}$ \\
\hline 1 & CORRECT SMILE LINE & $\mathbf{0}$ & 1 \\
\hline 2 & CORRECT FACIAL MIDLINE & 1 & 1 \\
\hline 3 & CORRECT TOOTH/ CROWN ALIGNMENT & $\mathbf{0}$ & 1 \\
\hline 4 & $\begin{array}{c}\text { ABSENCE OF VISIBLE TOOTH } \\
\text { DEFORMITY }\end{array}$ & $\mathbf{0}$ & 1 \\
\hline 5 & $\begin{array}{c}\text { ABSENCE OF VISIBLE TOOTH } \\
\text { DISCHROMY }\end{array}$ & $\mathbf{0}$ & 1 \\
\hline 6 & $\begin{array}{l}\text { ABSENCE OF VISIBLE GINGIVAL } \\
\text { DISCHROMY }\end{array}$ & 1 & 1 \\
\hline 7 & $\begin{array}{c}\text { ABSENCE OF VISIBLE GINGIVAL } \\
\text { RECESSIONS }\end{array}$ & 1 & $\mathbf{0}$ \\
\hline 8 & ABSENCE OF VISIBLE GINGIVAL EXCESS & 1 & 1 \\
\hline 9 & ABSENCE OF VISIBLE GINGIVAL SCARS & 1 & 1 \\
\hline \multirow[t]{2}{*}{10} & $\begin{array}{c}\text { ABSENCE OF VISIBLE DIASTEMA } \\
\text { AND/OR MISSING DENTAL PAPILLAE }\end{array}$ & 1 & 1 \\
\hline & $\begin{array}{l}\text { TOTAL SCORE (SEI) } \\
\end{array}$ & 5 & 9 \\
\hline
\end{tabular}
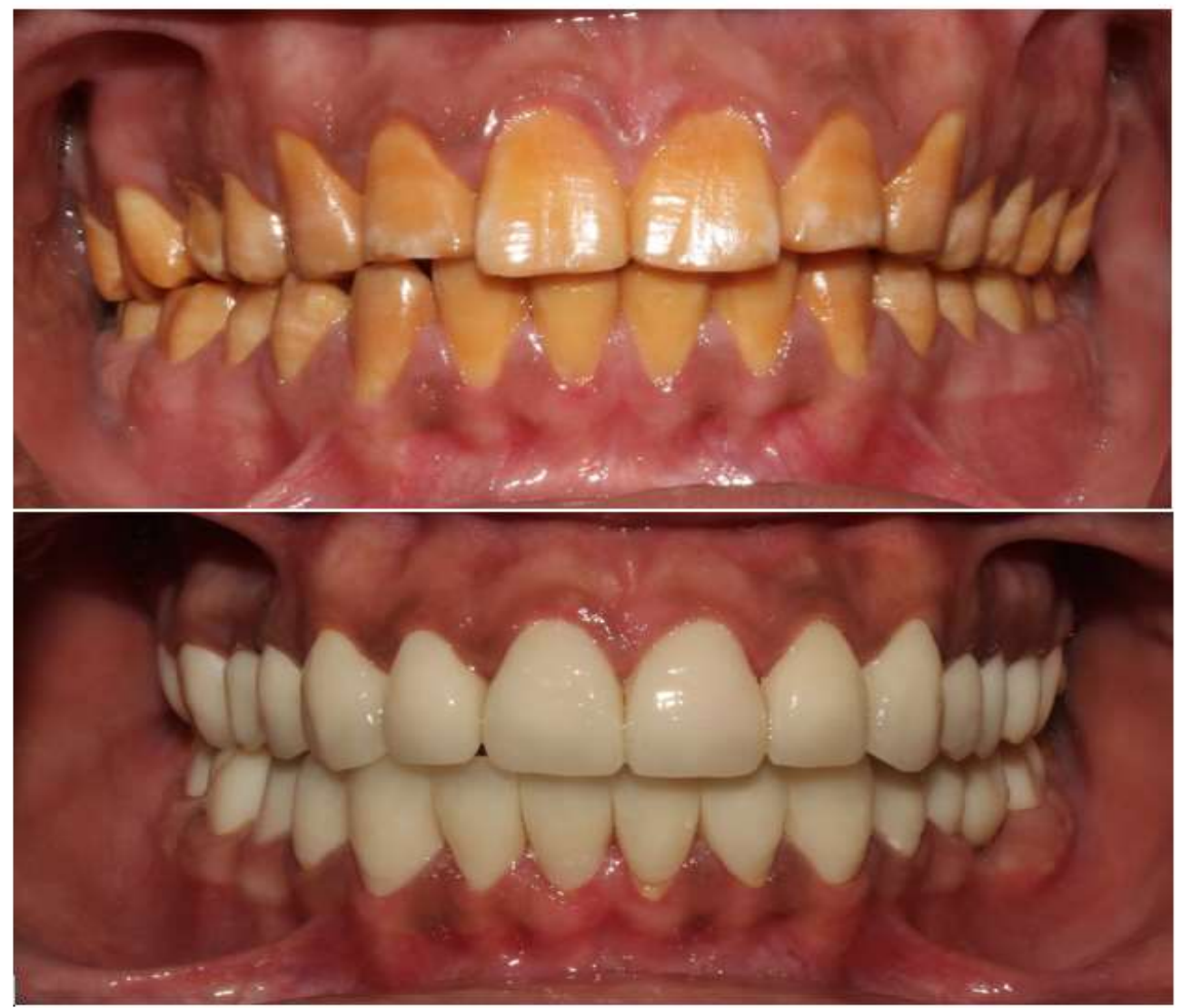

Figure 8: Intraoral frontal view in centric of preoperative dentition and postoperative final prosthesis 


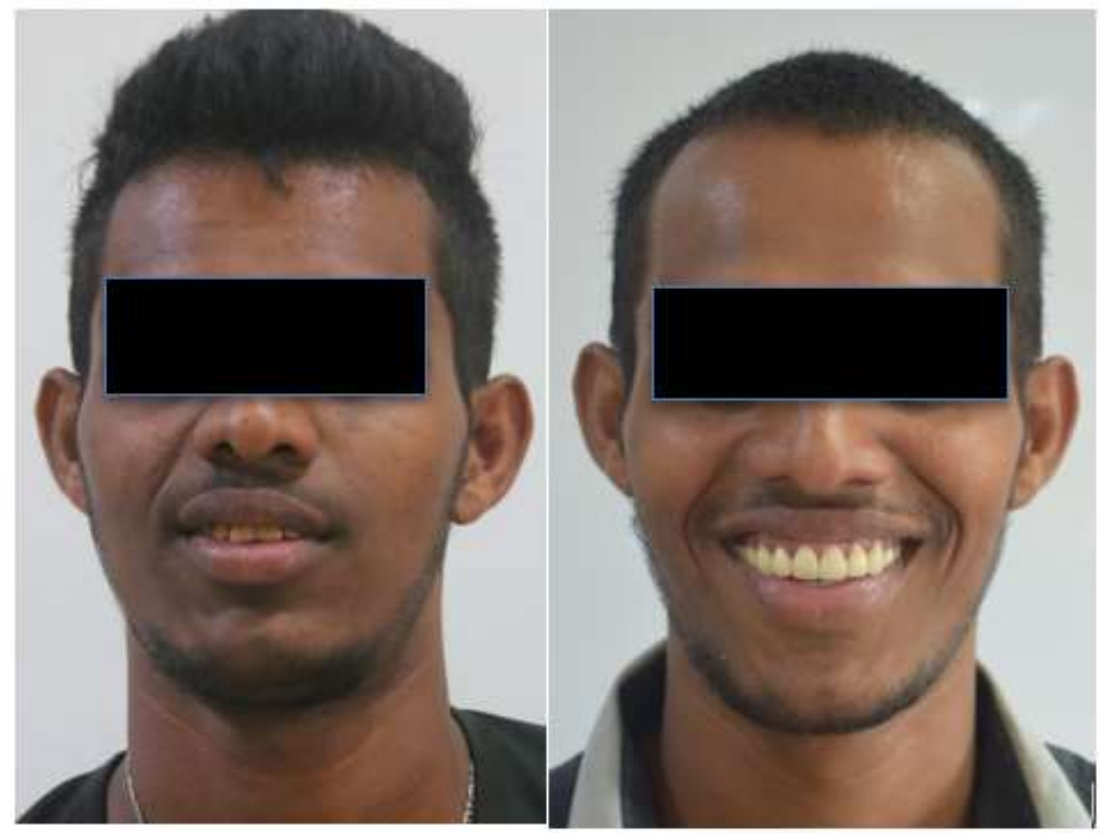

Figure 9: Preoperative and postoperative extraoral frontal view of the patient smile
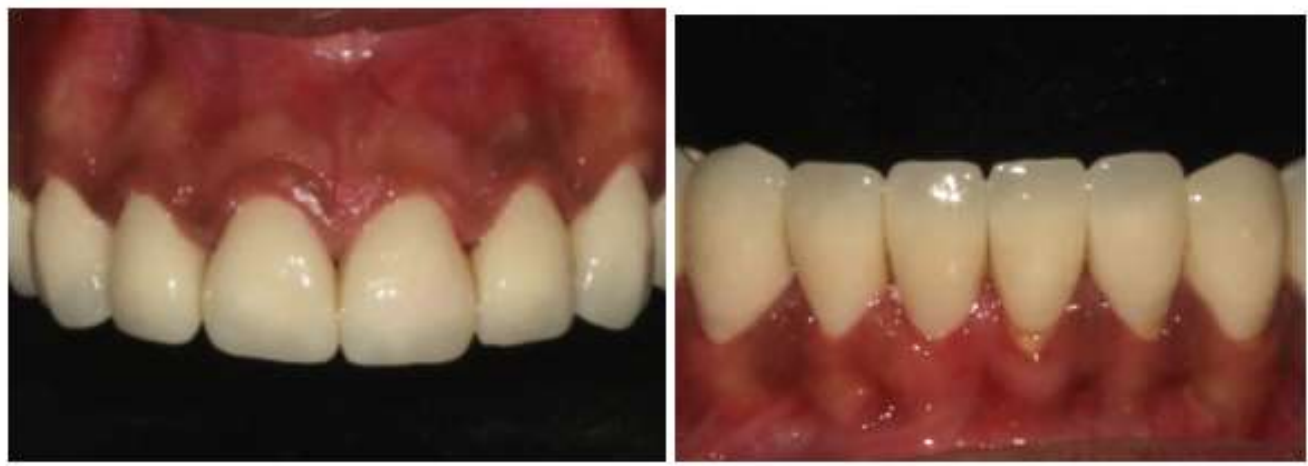

Figure 10: Intraoral close up of maxillary and mandibular anterior teeth of the final prosthesis

\section{RECALL AND REVIEW}

Patient was recalled after 1,3 and 6 months. He was advised meticulous oral hygiene instructions to brush twice daily and use floss interdentally. The patient had a high score of 27 preoperatively and a low score of 11 (Table 2) suggesting an improvement in oral health related quality of life (OHRQOL) using the OHIP-14 questionnaire [31-33].
The Visual analogue scale (VAS) (1-10) was used to evaluate the patient satisfaction of the patient after the treatment, with 0 (indicating complete dissatisfaction with the treatment) to 10 (indicating total satisfaction with the treatment) $[34,35]$. The score for which was 9. At 3 months' post cementation panoramic radiograph was taken (Figure 11). 
Table 2: Table showing the OHIP-14 score in each domain for the patient in this case report

\begin{tabular}{|c|c|c|}
\hline OHIP-14 DOMAINS & $\begin{array}{c}\text { PRE-TREATMENT SCORE FOR } \\
\text { EACH DOMAIN }\end{array}$ & $\begin{array}{c}\text { POST-TREATMENT SCORE FOR } \\
\text { EACH DOMAIN }\end{array}$ \\
\hline Functional limitation & 3 & 1 \\
\hline Physical pain & 3 & $\mathbf{3}$ \\
\hline Psychological discomfort & 6 & 2 \\
\hline Physical disability & 2 & 2 \\
\hline Psychological disability & 6 & 2 \\
\hline Social disability & 4 & 0 \\
\hline Handicap & 3 & 11 \\
\hline
\end{tabular}

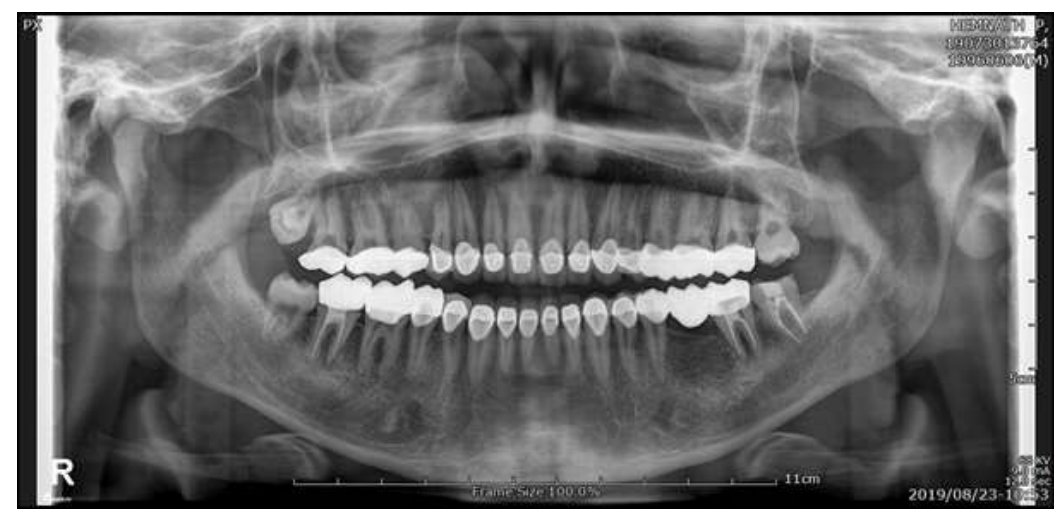

Figure 11: Panoramic Radiograph at 3 months' post cementation

\section{DISCUSSION}

The enamel during organogenesis, changes from a soft and pliable tissue to its final form, this is almost devoid of protein $[\mathbf{1}, \mathbf{3 6}$, 37]. Any deviation from this process can lead

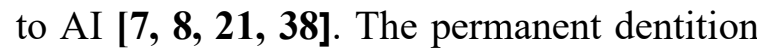
is more commonly affected as seen in the case presented here [39-41]. Various studies showed that oral complaints associated with AI are esthetic appearance, extensive loss of tooth structure, dental sensitivity, and loss of vertical dimension [20, 42-44]. No standard formula for successful treatment of AI has been demonstrated.

Treatment planning for patients with $\mathrm{AI}$ is dependent on many factors like the age, socioeconomic status of the patient, the type and severity of the disorder, and the intraoral scenario at the time the treatment is planned. The skill of a prosthodontist often lies in overcoming the challenges that are faced in the treatment planning and execution with expected results [45]. It includes removal of surface stains, reducing sensitivity, maintaining vertical dimension of occlusion, and the esthetics with adhesive techniques/overdentures/porcelain-fused-to metal crowns/fixed partial dentures/full porcelain crowns/inlay/onlay restorations are used for better esthetics of the patients [1, 46-52] . 
Although many dental prosthetic options are available in this present case we chose. This being said a full coverage restoration in order to protect the soft texture of enamel $[\mathbf{5 0}, \mathbf{5 2}]$. Zirconia copings layered with ceramic for anterior teeth and monolithic crowns for posterior teeth were the apt selection of material for prosthesis for this patient, as it was essential to mask the enamel discolouration completely [53-57]. A porcelain fused to metal prosthesis could exhibit metallic hue and compromise esthetics, which was of utmost importance for this case $[49,50,52]$.

Since the bonding protocol is usually extensive for teeth with structural abnormalities, a resin cement with meticulous etching and bonding protocol is generally used [58-61]. We went ahead with the conventional permanent Type I GIC luting agent, since the enamel was defective and tooth preparation was on dentin which cannot be etched.

In recent times, the most important challenge in any prosthetic full mouth rehabilitation is the time constraint in the complete treatment procedure. In the present case, the treatment was completed in a short span of 1 month with a minimum of 6 clinical appointments.

\section{CONCLUSION}

Rehabilitating a patient with amelogenesis Imperfecta dysplasia with multiple disorders is challenging and requires careful treatment planning. Majority of these patients are very young with high esthetic and functional demands. Fixed rehabilitation of such patients with esthetic dental material would be an ideal choice of treatment. The appropriate treatment protocol for these patients not only satisfies their aesthetic and functional demands but also gives better confidence in life.

\section{ACKNOWLEDGEMENT}

The authors acknowledge Saveetha University for all the help and support.

\section{SOURCE OF SUPPORT}

Nil

\section{CONFLICT OF INTEREST}

None declared.

\section{REFERENCES}

[1] Wilson L, Bradshaw JP, Marks MK. Amelogenesis Imperfecta, Facial Esthetics and Snap-On Smile. J Tenn Dent Assoc. 2015; 95(1): 18-21; quiz 22-3.

[2] Ceyhan D, Kirzioglu Z, Emek T. A long-term clinical study on individuals with amelogenesis imperfecta. Niger J Clin Pract. 2019 Aug; 22(8): 1157-62. 
[3] Bandaru BK, Thankappan P, Kumar Nandan SR, Amudala R, Annem SK, Rajendra Santosh AB. The prevalence of developmental anomalies among school children in Southern district of Andhra Pradesh, India. J Oral Maxillofac Pathol. 2019 Jan; 23(1): 160.

[4] Turkün LS. Conservative restoration with resin composites of a case of amelogenesis imperfecta. Int Dent J. 2005 Feb; 55(1): 38-41.

[5] Kirzioglu Z, Ulu KG, Sezer MT, Yüksel S. The relationship of amelogenesis imperfecta and nephrocalcinosis syndrome. Med Oral Patol Oral Cir Bucal. 2009 Nov 1; 14(11): e579-82.

[6] Nikolopoulos G, Smith CEL, Brookes SJ, El-Asrag ME, Brown CJ, Patel A, et al. New missense variants in RELT causing hypomineralised amelogenesis imperfecta. Clin Genet. 2020 May; 97(5): 688-95.

[7] Kim YJ, Kang J, Seymen F, Koruyucu M, Zhang H, Kasimoglu Y, et al. Alteration of Exon Definition Causes Amelogenesis Imperfecta. J Dent Res. 2020 Apr; 99(4): 410-8.

[8] Laugel-Haushalter V, Bär S, Schaefer E, Stoetzel C, Geoffroy V, Alembik
$\mathrm{Y}$, et al. A New Homozygous

Missense Mutation Responsible for a Milder Phenotype of Skeletal Dysplasia with Amelogenesis Imperfecta. Front Genet. 2019 May 28; 10: 504.

[9] Li L, Saiyin W, Zhang H, Wang S, $\mathrm{Xu} \mathrm{Q}$, Qin $\mathrm{C}$, et al. FAM20A is essential for amelogenesis, but is dispensable for dentinogenesis. J Mol Histol. 2019 Dec; 50(6): 581-91.

[10] Kammoun R, Zmantar T, Labidi A, Abbes I, Mansour L, Ghoul-Mazgar S. Dental caries and hypoplastic amelogenesis imperfecta: Clinical, structural, biochemical and molecular approaches. Microb Pathog. 2019 Oct; 135: 103615.

[11] Duan X, Yang S, Zhang H, Wu J, Zhang Y, Ji D, et al. A Novel Mutation, Its Phenotypic Features, and Skewed X Inactivation. J Dent Res. 2019 Jul; 98(8): 870-8.

[12] Smith CEL, Poulter JA, Brookes SJ, Murillo G, Silva S, Brown CJ, et al. Phenotype and Variant Spectrum in the LAMB3 Form of Amelogenesis Imperfecta. J Dent Res. 2019 Jun; 98(6): 698-704.

[13] Hirji N, Bradley PD, Li S, Vincent A, Pennesi ME, Thomas AS, et al. 
Jalili Syndrome: Cross-sectional and Longitudinal Features of Seven Patients With Cone-Rod Dystrophy and Amelogenesis Imperfecta. Am J Ophthalmol. 2018 Apr; 188: 12330.

[14] Manoj V, Sandeepa NC, Selvamani M, Panjami M. Association of enamel-renal syndrome with sialolith: A rare entity. $\mathrm{J}$ Oral Maxillofac Pathol. 2019 Feb; 23 (Suppl 1): 126-9.

[15] Maia CMF, Machado RA, Gil-daSilva-Lopes VL, Lustosa-Mendes E, Rim PHH, Dias VO, et al. Report of two unrelated families with Jalili syndrome and a novel nonsense heterozygous mutation in CNNM4 gene. Eur J Med Genet. 2018 Jul; 61(7): 384-7.

[16] Kammoun R, Behets C, Mansour L, Ghoul-Mazgar S. Mineral features of connective dental hard tissues in hypoplastic amelogenesis imperfecta. Oral Dis. 2018 Apr; 24(3): 384-92.

[17] Hegde S. Multiple Unerupted Teeth with Amelogenesis Imperfecta in Siblings. North American Journal of Medical Sciences. 2012; 4: 235.

[18] DeSort KD. Amelogenesis imperfecta: The genetics, classification, and treatment. The Journal of Prosthetic Dentistry. 1983; 49: 786-92.

[19] Witkop CJ. Amelogenesis imperfecta, dentinogenesis imperfecta and dentin dysplasia revisited: problems in classification. Journal of Oral Pathology and Medicine 1988; 17: 547-53.

[20] Sundell S, Koch G. Hereditary amelogenesis imperfecta. I. Epidemiology and clinical classification in a Swedish child population. Swed Dent J. 1985; 9(4): 157-69.

[21] Wright T. Amelogenesis imperfecta. European Journal of Oral Sciences. 2011; 119: 338-41.

[22] Pavlič A, Lukinmaa P-L, Nieminen P, Kiukkonen A, Alaluusua S. Severely hypoplastic amelogenesis imperfecta with taurodontism. International Journal of Paediatric Dentistry. 2007; 17: 259-66.

[23] Canger EM, Çelenk P, Yenísey M, Odyakmaz SZ. Amelogenesis Imperfecta, hypoplastic type associated with some dental abnormalities: a case report. Brazilian Dental Journal. 2010; 21: 
$170-4$.

[24] Peters E, Cohen M, Altini M. Rough hypoplastic amelogenesis imperfecta with follicular hyperplasia. Oral Surgery, Oral Medicine, Oral Pathology. 1992; 75: 87-92.

[25] Abduo J, Bennamoun M, Tennant M, McGeachie J. Effect of prosthodontic planning on lateral occlusion scheme: a comparison between conventional and digital planning. J Appl Oral Sci. 2015 Mar; 23(2): 196-205.

[26] Singh RG, Sinha P. Functional and Aesthetic Full Mouth Rehabilitation of a Severely Worn Dentition to Restore Vertical Dimension: A Case Report. J Indian Prosthodont Soc. 2014 Dec; 14(Suppl 1): 210-4.

[27] Hobo S, Takayama H. Oral Rehabilitation: Clinical

Determination of Occlusion. Quintessence Publishing Company; 1997. $168 \mathrm{p}$.

[28] Dawson PE. Functional Occlusion: From TMJ to Smile Design. Mosby Incorporated; 2007. $630 \mathrm{p}$.

[29] Rotundo R, Nieri M, Bonaccini D, Mori M, Lamberti E, Massironi D, et al. The Smile Esthetic Index
(SEI): A method to measure the esthetics of the smile. An intra-rater and inter-rater agreement study. Eur J Oral Implantol. 2015 Winter; 8(4): 397-403.

[30] Aschheim KW, Singer BA. Fundamentals of esthetics and smile analysis. Esthetic Dentistry. 2015. p: $38-54$.

[31] Kuoppala R, Näpänkangas $R$, Raustia A. Quality of Life of Patients Treated With ImplantSupported Mandibular Overdentures Evaluated With the Oral Health Impact Profile (OHIP-14): a Survey of 58 Patients. J Oral Maxillofac Res. 2013 Jul 1; 4(2): e4.

[32] Schierz O, Baba K, Fueki K. Functional Oral Health-Related Quality of Life Impact: A Systematic Review in Populations with Tooth Loss. J Oral Rehabil [Internet]. 2020 Apr 24; Available from:

http://dx.doi.org/10.1111/joor.12984

[33] Cho M-J. The relationship between masticatory ability and the quality of life oral health- related using OHIP14 of the elderly. Journal of Digital Convergence. 2016 ; 14: 341-8.

[34] Heydecke G, Klemetti E, Awad 
MA, Lund JP, Feine JS.

Relationship between prosthodontic evaluation and patient ratings of mandibular conventional and implant prostheses. Int J Prosthodont. 2003 May; 16(3): 30712.

[35] Voutilainen A, Pitkäaho T, Kvist T, Vehviläinen-Julkunen K. How to ask about patient satisfaction? The visual analogue scale is less vulnerable to confounding factors and ceiling effect than a symmetric Likert scale., Journal of Advanced Nursing. 2016; 72: 946-57.

[36] Nikaido $T$, Takagaki $T$, Sato $T$, Burrow MF, Tagami J. The concept of super enamel formation Relationship between chemical interaction and enamel acid-base resistant zone at the self-etch adhesive/enamel interface. Dent Mater J 2020.

[37] Dental Enamel Formation to Destruction. 2017.

[38] Markovich D, Petrovich B, Perich T. Clinical Studies And Rehabilitation Of The Oral Cavity Of Patients Suffering From Imperfect Amelogenesis (Amelogenesis Imperfecta). Actual problems in dentistry. $2016 ; 12: 29$ 39.

[39] Faria-E-Silva Al, De Moraes RR, De Sousa Menezes M, Capanema RR, De Moura AS, Martelli-Júnior H. Hardness And Microshear Bond Strength To Enamel And Dentin Of Permanent Teeth With Hypocalcified Amelogenesis Imperfecta. International Journal Of Paediatric Dentistry. 2011; 21:31420.

[40] Sekiguchi H, Tanakamaru H, Minaguchi K, Machida Y, Yakushiji M. A Case of Amelogenesis Imperfecta of Deciduous and All Permanent Teeth. The Bulletin of Tokyo Dental College. 200; 42: 4550.

[41] Sharma K. Genetic determinants and dynamics of permanent teeth emergence in Northwest Indian twins: A chronogenetic study. HOMO. 2014; 65: 450-63.

[42] İzgi $A D$, Kale $\mathrm{E}, \mathrm{Niğiz} \mathrm{R}$. Amelogenesis Imperfecta: Rehabilitation and Brainstorming on the Treatment Outcome after the First Year. Case Rep Dent. 2015 Dec 13; 2015: 579169.

[43] Young H. Amelogenesis Imperfecta, 
Hypodontia and Impacted Teeth - a challenging case for rehabilitation [Internet]. Available from: http://dx.doi.org/10.26226/morressie r.5949277cd462b80296c9eada

[44] Hegde S. Amelogenesis Imperfecta, Hypoplastic Type with Multiple Impacted Teeth - A Case Report. International Journal of Dental Medicine. 2018; 4: 27.

[45] Rajaraman V, Velayudhan A. Full Mouth Fixed Rehabilitation of a Young Adult with Ectodermal Dysplasia: Making Mountain Out of a Molehill in The Literal Sense. J Dent Oral Sci. 2020; 2(2): 1-12.

[46] Rizzo NSP, da Cunha LF, Sotelo BV, Gonzaga CC, Correr GM, Gaião U. Esthetic Rehabilitation with Direct Composite Resin in a Patient with Amelogenesis Imperfecta: A 2-Year Follow-Up. Case Rep Dent. 2019 Aug 14; 2019: 8407025.

[47] Zagdoon A. Amelogenesis Imperfecta : Review Of Treatment Modalities [Internet]. 2017. p. 9.

[48] Ganapathy D, Sasikumar S, Sekhar P. Full mouth rehabilitation of a patient with amelogenesis imperfecta: A clinical report. Indian Journal of Multidisciplinary Dentistry. 2015 Jan 1; 5(1): 47.

[49] Strauch S, Hahnel S. Restorative Treatment in Patients with Amelogenesis Imperfecta: A Review. Journal of Prosthodontics. 2018; 27: 618-23.

[50] Lamb DJ. The treatment of amelogenesis imperfecta. The Journal of Prosthetic Dentistry. 1976; 36: 286-91.

[51] Brezulier D. Description of a CAD Protocol for the Simulation of Dental Treatment of Amelogenesis Imperfecta. Biomedical Journal of Scientific \& Technical Research. 2018; 3 .

[52] Sabandal MMI, Schäfer E. Amelogenesis imperfecta: review of diagnostic findings and treatment concepts. Odontology. 2016; 104: 245-56.

[53] Vaishali K. 34. Marginal fit of metal ceramic copings fabricated with slm technique and cad cam fabricated zirconia copings. The Journal of Indian Prosthodontic Society. 2018; 18: 66.

[54] High strength CAD/CAM fabricated veneering material sintered to 
zirconia copings - A new fabrication mode for all-ceramic restorations. The Journal of Prosthetic Dentistry. 2009; 102: 171.

[55] P S, R N, Reddy S, Reddy S. Shear Bond Strength of Ceramic Bonded to Different Core Materials and Their Pattern of Failure: An In Vitro Study. Cureus. 2019 Nov 26; 11(11): e6242.

[56] Al Hamad KQ, Obaidat II, Baba NZ. The Effect of Ceramic Type and Background Color on Shade Reproducibility of All-Ceramic Restorations. J Prosthodont. 2020 Jul; 29(6): 511-7.

[57] Andreiuolo RF, Sabrosa CE, Cervantes Dias KRH. Dual-scan technique for the customization of zirconia computer-aided design/computer-aided manufacturing frameworks. Eur $\mathrm{J}$ Dent. 2013 Sep; 7(Suppl 1): S1158.

[58] Xie H, Haifeng XIE, Chen C, Wenyong DAI, Chen G, Zhang F. In vitro short-term bonding performance of zirconia treated with hot acid etching and primer conditioning etching and primer conditioning. Dental Materials Journal. 2013; 32: 928-38.

[59] Scaminaci Russo D, Cinelli F, Sarti C, Giachetti L. Adhesion to Zirconia: A Systematic Review of Current Conditioning Methods and Bonding Materials. Dent J 2019 Aug 1; 7(3).

[60] Lee Y, Oh KC, Kim N-H, Moon HS. Evaluation of Zirconia Surfaces after Strong-Acid Etching and its Effects on the Shear Bond Strength of Dental Resin Cement. Int J Dent. 2019 Jul 1; 2019: 3564275.

[61] Xiang D, Lin H. [Research progress in surface bonding pretreatment of dental zirconia ceramics]. Zhonghua Kou Qiang Yi XueZaZhi. 2020 May 9; 55(5): 348-52. 